\title{
KORELASI ANTARA INTERVAL S2-OPENING SNAP DAN MITRAL VALVE AREA YANG DIIDENTIFIKASI DENGAN COLOR SPECTROGRAPH PHONOCARDIOGRAPHY PADA PASIEN MITRAL STENOSIS
}

\author{
Iman Y. Suhartono \\ Terrance Ransun, Michael S. Kawilarang, Elfan Moeljono, Fonny M. Tedjo \\ Agnes L. Panda, Jan H. Awaloei, Reginald L. Lefrandt \\ Departemen Kardiologi dan Kedokteran Vaskular Fakultas Kedokteran \\ Universitas Sam Ratulangi Manado/RSUP Prof. Dr. R.D. Kandou Manado \\ Email:iman.yulianto@gmail.com
}

\begin{abstract}
Color spectrograph phonocardiography (CSP) is a method for recording heart sounds by using a digital stethoscope. The recorded result can be analyzed by using a soft ware. CSP can identify the opening snap (OS) and measure the S2-OS interval. This study aimed to determine the correlation between adjusted S2-OS to the mitral valve area (MVA) in mitral stenosis (MS) patients. The samples were MS patients admitted to the ICCU and the ward of Prof. Dr. R.D. Kandou Hospital, Manado. Patients with atrial fibrillation were excluded. Every patient underwent echocardiography and CSP to obtain the MVA and S2-OS interval. The adjusted S2-OS interval is the S2-OS interval divided by the number of heart beats (milisecond/beat per minute). Variables were analyzed by using the Pearson correlation test. The results showed that there were 14 MS patients involved in this study. There was a strong correlation between adjusted S2-OS interval and MVA. Estimated MVA was obtained by using the formula MVA $=-1.358+2.07$. Conclusion: The adjusted S2-OS interval was strongly correlated to the MVA of MS Patients and could predict the MVA value.
\end{abstract}

Keywords: color spectrograph phonocardiography, S2-OS interval, mitral valve area, mitral stenosis, echocardiography.

\footnotetext{
Abstrak: Color spectrograph phonocardiography (CSP) merupakan metode merekam bunyi jantung dengan menggunakan stetoskop digital. Hasil rekaman ini dapat dianalisis dengan piranti lunak. CSP dapat mengidentifikasi opening snap (OS) dan mengukur interval S2 - OS. Penelitian ini bertujuan untuk mendeteksi korelasi antara interval S2-OS yang sudah disesuaikan dengan mitral valve area (MVA) pada pasien mitral stenosis (MS). Sampel penelitian ialah pasien mitral stenosis yang dirawat di ICCU dan bangsal BLU RSUP Prof. Dr. R.D. Kandou Manado. Pasien dengan atrial fibrilasi dieksklusi. Masing-masing pasien menjalani pemeriksaan echocardiography dan CSP untuk memperoleh MVA dan interval S2OS. Interval S2-OS yang telah disesuaikan adalah interval S2-OS yang dibagi dengan denyut jantung (milidetik/denyut jantung per menit). Variabel-variabel tersebut dianalisis dengan menggunakan analisis korelasi Pearson. Hasil penelitian memperlihatkan sebanyak 14 pasien mitral stenosis diikutsertakan dalam penelitian. Terdapat korelasi sangat kuat antara interval S2-OS yang telah disesuaikan dengan MVA. Estimasi MVA dapat diperoleh dari persamaan MVA $=-1,358+2,07$. (Interval S2-OS yang telah disesuaikan). Simpulan: Interval S2-OS yang telah disesuaikan memiliki korelasi yang sangat kuat dengan MVA pada pasien-pasien mitral stenosis. Interval S2-OS yang telah disesuaikan dapat memperkirakan nilai MVA.

Kata kunci: color spectrograph phonocardiography, interval S2-OS, mitral valve area, mitral stenosis, echocardiography.
} 
Mitral stenosis(MS) adalah keadaan di mana luas penampang katup mitral $<2,5$ $\mathrm{cm}^{2}$. Mitral stenosis merupakan penyakit yang cukup sering dijumpai terutama di negara berkembang seperti Indonesia. Hal ini disebabkan masih banyaknya kejadian demam rematik akut di negara berkembang. ${ }^{2}$ Diagnosis MS ditegakkan dengan menggunakan anamnesis, pemeriksaan fisik, dan pemeriksaan penunjang. Auskultasi pada pemeriksaan fisik menunjukkan adanya pengerasan $\mathrm{S} 1$, opening snap (OS), dan murmur diastolik dekresendo serta murmur presystolic accentuation. ${ }^{3}$

Derajat beratnya MS saat ini ditentukan dengan menggunakan pemeriksaan penunjang modern seperti echocardiography dan kateterisasi jantung. ${ }^{4}$ Saat ini tidak semua fasilitas kesehatan di negara berkembang, seperti di Indonesia, menyediakan alat pemeriksaan penunjang tersebut. Derajat MS diperlukan oleh para dokter untuk menentukan tatalaksana selanjutnya.

Opening snap merupakan bunyi yang berasal dari tegangan korda tendinae dan daun katup yang mengalami stenosis. ${ }^{5}$ Opening snap mempunyai sifat bernada tinggi, dengan intensitas tidak begitu kuat, dan paling baik didengar di daerah apeks dengan menggunakan membran. ${ }^{1,5}$
Color spectrograph phonocardiography (CSP) merupakan suatu metode perekaman bunyi jantung dan menyajikan hasil rekaman tersebut dalam bentuk spektrograf berwarna (Gambar 1). ${ }^{6}$ Hasil dari rekaman tersebut dapat dianalisis dan memberikan informasi yang berkaitan dengan bunyi jantung. Pada CSP, OS dikenali sebagai bunyi dengan frekuensi lebih tinggi dari bunyi jantung kedua, muncul sesaat sesudah bunyi jantung kedua, dan tepat sesaat sebelum murmur diastolik (Gambar 2). ${ }^{5}$

CSP terdiri dari stetoskop digital, USB Bluetooth dongle, dan komputer. ${ }^{6}$ Bunyi jantung direkam dengan menggunakan stetoskop digital. Data rekaman tersebut dipindahkan melalui USB Bluetooth dongle ke komputer. Data rekaman tersebut diolah dengan menggunakan piranti lunak. Penelitian ini menggunakan stetoskop digital bermerk Littmann 3200 dengan piranti lunak Stethassist versi 1.0.

Interval antara S2 dengan OS (S2-OS) berhubungan dengan derajat MS. Waktu yang diperlukan katup mitral untuk membuka bergantung pada besarnya perbedaan tekanan antara atrium kiri dan ventrikel kiri. Semakin berat derajat MS maka semakin tinggi tekanan di atrium kiri sehingga semakin awal katup mitral terbuka. ${ }^{1}$

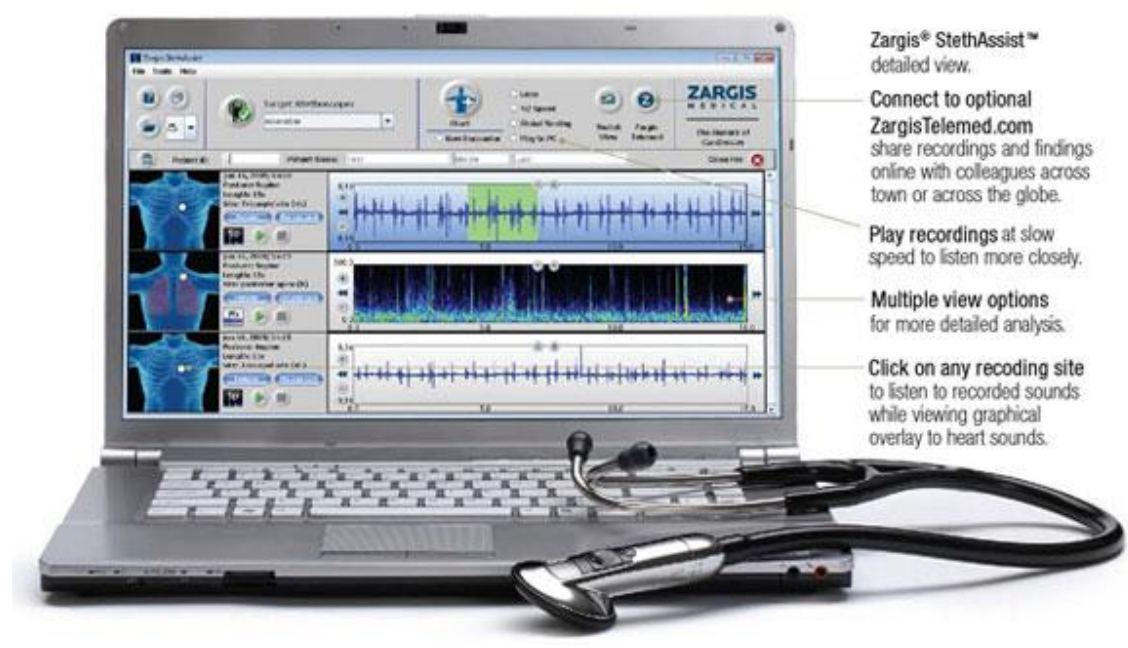

Gambar 1. Color Spectrograph Phonocardiography. Bagian sebelah kiri layar monitor menunjukkan letak dimana perekaman dilakukan. Gambar sebelah kanan menunjukkan spektrum bunyi yang dihasilkan. Warna menunjukkan intesitas dari bunyi, mulai dari biru, hijau, kuning, sampai merah. Sumber: Sarbandi et al., 2011. ${ }^{6}$ 
Telah banyak dilakukan penelitian yang menyelidiki hubungan antara interval S2-OS dan MVA, namun sampai saat ini belum ada penelitian mengenai hubungan antara interval S2-OS yang sudah disesuaikan dan denyut jantung terhadap derajat MS.

Penelitian ini bertujuan untuk menyelidiki hubungan antara interval S2-OS yang sudah disesuaikan dengan denyut jantung terhadap mitral valve area (MVA). Penelitian ini juga berusaha menemukan suatu persamaan untuk mengestimasi MVA pasien MS dari interval S2-OS. Diharapkan hasil penelitian ini dapat digunakan untuk membantu para dokter di daerah perifer dalam mengestimasi MVA dan menentukan derajat MS.

\section{METODE PENELITIAN}

Penelitian ini merupakan penelitian observasi dan analisis. Sampel penelitian ini ialah pasien MS yang dirawat di Intensive Cardiac Care Unit (ICCU) dan bangsal Irina F BLU RSUP Prof. Dr. R.D. Kandou Manado dari Mei 2011 sampai dengan Januari 2013. Pasien harus mempunyai klinis opening snap dan telah menandatangani informed consent. Pasienpasien dengan fibrilasi atrial dieksklusi.

Setiap pasien menjalani pemeriksaan ekokardiografi untuk mendapatkan nilai MVA. Nilai MVA didapatkan dengan menggunakan metode pressure half time (PHT) dan/atau planimetri. Pemeriksaan ekokardiografi dilakukan oleh tiga orang dokter spesialis jantung dan pembuluh darah yang telah memiliki standar kompetensi di bidangnya. Pemeriksaan CSP dilakukan oleh residen Bagian Kardiologi dan Kedokteran Vaskuler Fakultas Kedokteran Unsrat Manado. Pemeriksa CSP tidak mengetahui terlebih dahulu hasil MVA yang didapatkan dari ekokardiografi.

Interval S2-OS diperoleh dengan mengukur waktu dari tengah-tengah S2 sampai tengah-tengah OS. Pengukuran dilakukan pada irama yang reguler sebanyak tiga kali dan diambil nilai rata-rata. Pengukuran denyut nadi dilakukan dengan menggunakan data dari CSP pada denyut yang sama dan diambil nilai tengah dari tiga pengukuran. Interval S2-OS yang sudah disesuaikan dibagi dengan denyut jantung untuk mendapatkan hasil interval S2-OS yang sudah disesuaikan.

Variabel-variabel tersebut dianalisis dengan menggunakan analisis korelasi Pearson untuk mendapatkan korelasi antara interval S2-OS dengan MVA serta interval S2-OS yang sudah disesuaikan dengan MVA. Piranti lunak SPSS versi 18.0 digunakan dalam mempermudah analisis ini.

\section{HASIL PENELITIAN}

Sampel penelitian ini berjumlah 14 orang, mayoritas perempuan $(79 \%)$ dengan deskripsi rerata: rerata usia 38 tahun, luas permukaan tubuh $1,49 \mathrm{~m}^{2}$, dan denyut nadi 80 . Dua pasien dengan denyut nadi $>100$ dan 2 orang pasien dengan denyut nadi $<60$. Sebagian besar pasien termasuk kelompok MS berat (7 orang), sedangkan kelompok MS ringan berjumlah 2 orang. Hasil karakterikstik sampel penelitian ditampilkan dalam Tabel 1.

Tabel 1. Karakteristik dasar pasien-pasien

\begin{tabular}{lc}
\hline \multicolumn{1}{c}{ Variabel } & Nilai $( \pm \mathrm{SD})$ \\
\hline Usia (tahun), mean $(\mathrm{SD})$ & $38,91( \pm 15,62)$ \\
Laki-laki, $\mathrm{n}(\%)$ & 3,21 \\
Luas permukaan tubuh, & $1,49( \pm 0,18)$ \\
mean (SD) & $80,4( \pm 23,3)$ \\
Denyut nadi & \\
Derajat MS, n (\%) & $2(14)$ \\
$\quad$ - Ringan & $5(36)$ \\
- Sedang & $7(50)$ \\
- Berat &
\end{tabular}

Interval S2-OS baik yang belum maupun yang sudah disesuaikan dengan denyut jantung dan MVA disajikan dalam Tabel 2. Interval S2-OS disajikan dalam satuan detik sedangkan interval S2-OS yang sudah disesuaikan ditampilkan dalam satuan $10^{3}$. milidetik $^{-1}$. 


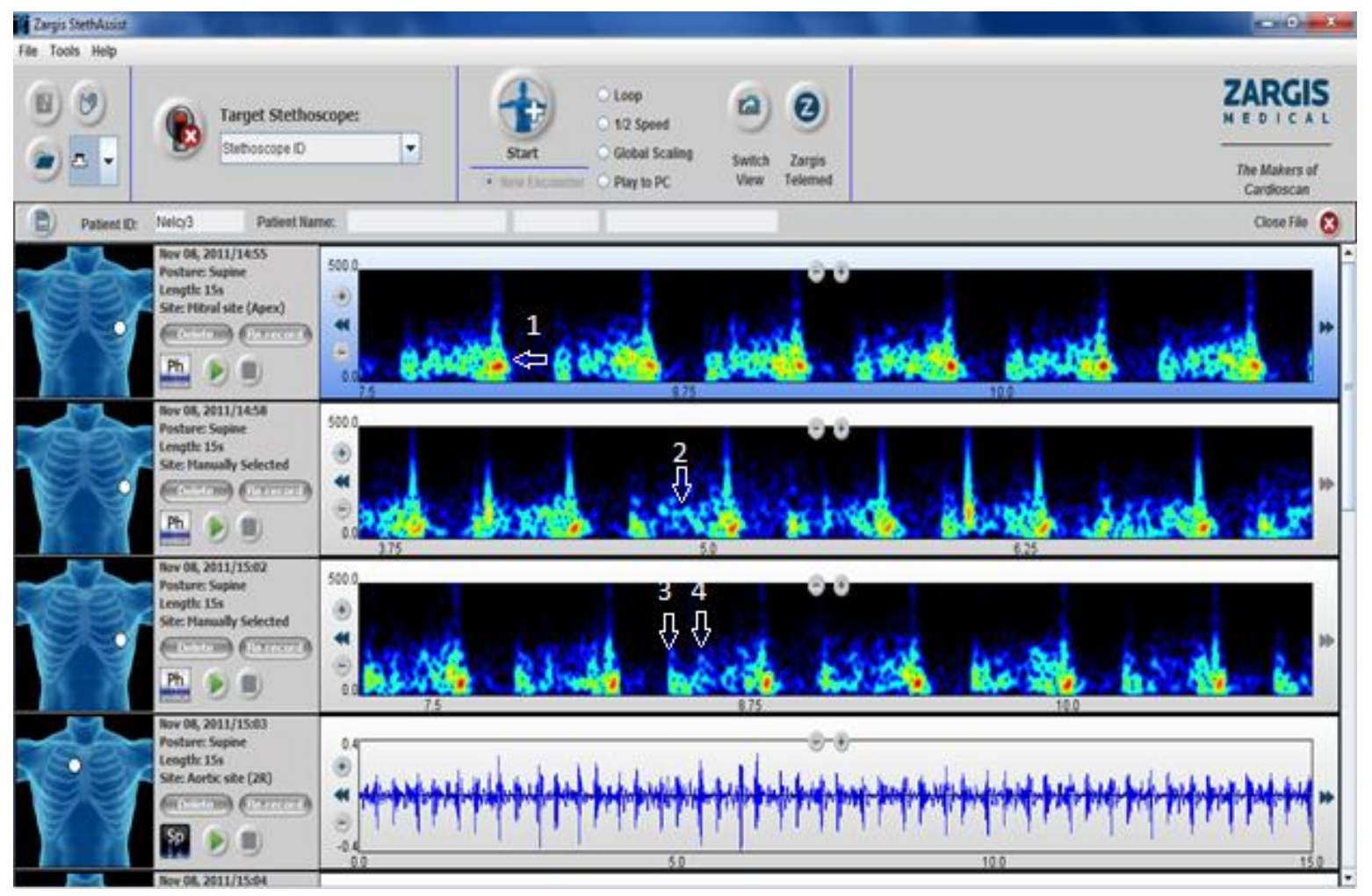

Gambar 2. Hasil rekaman CSP pada pasien mitral stenosis. Anak panah 1 menunjukkan bunyi M1 yang mengeras; anak panah 2 menunjukkan bising diastolik; anak panah 3 menunjukkan bunyi jantung kedua; dan anak panah ketiga menunjukkan opening snap.

Tabel 2. Interval S2-OS, interval S2-OS yang sudah disesuaikan, dan mitral valve area.

\begin{tabular}{ccc}
\hline $\begin{array}{c}\text { Interval } \\
\text { S2-OS } \\
(\text { detik) }\end{array}$ & $\begin{array}{c}\text { Interval S2-OS yang } \\
\text { sudah disesuaikan }^{\left(\mathbf{1 0}^{\mathbf{3}} \text {.milidetik } \mathbf{- 1}\right)}\end{array}$ & $\begin{array}{c}\text { MVA } \\
\left.\mathbf{( c m}^{\mathbf{2}}\right)\end{array}$ \\
\hline 0,054 & 0,62 & 0,21 \\
0,078 & 0,77 & 0,24 \\
0,082 & 1,11 & 0,5 \\
0,060 & 1,11 & 0,59 \\
0,084 & 1,16 & 0,7 \\
0,089 & 1,12 & 0,7 \\
0,072 & 1,04 & 0,9 \\
0,105 & 1,17 & 1,1 \\
0,120 & 1,17 & 1,21 \\
0,100 & 1,21 & 1,3 \\
0,095 & 1,30 & 1,3 \\
0,119 & 1,20 & 1,5 \\
0,100 & 1,44 & 1,8 \\
0,108 & 1,50 & 1,89 \\
\hline
\end{tabular}

Analisis korelasi Pearson antara interval S2-OS yang sudah disesuaikan dengan MVA menunjukkan hubungan positif yang sangat bermakna dengan $\mathrm{r}=$ 0,881 dan $P<0,001$. Korelasi ini lebih kuat daripada korelasi antara interval S2-OS yang belum disesuaikan dengan MVA ( $\mathrm{r}=$ 0,775 dan $P<0,005)$.

Dari data tersebut dapat disusun sebuah persamaan estimasi MVA dengan menggunakan variabel interval S2-OS. Persamaan tersebut didapatkan dengan menggunakan metode regresi linear sederhana. Persamaan tersebut dapat ditulis sebagai berikut: MVA $=-1,358+2,07$ (interval S2-OS yang sudah disesuaikan)

\section{BAHASAN}

Beberapa penelitian telah menemukan adanya korelasi antara interval S2-OS dengan derajat MS. Kalmanson et al. ${ }^{7}$ menunjukkan adanya hubungan antara periode relaksasi isovolumetrik dengan derajat MS. Ebringer et $\mathrm{al}^{8}$ mengemukakan terdapatnya hubungan bermakna antara faktor-faktor hemodinamik dan interval S2OS namun tidak terdapat hubungan ber- 
makna antara interval S2-OS dan MVA. ${ }^{8}$

Pada penelitian ini, didapatkan adanya hubungan yang sangat kuat antara interval S2-OS dengan MVA baik sebelum disesuaikan maupun sesudah disesuaikan. Hubungan antara interval S2-OS yang sudah disesuaikan menunjukkan korelasi yang lebih kuat.

Opening snap sangat dipengaruhi oleh perbedaan tekanan antara atrium kiri dan ventrikel kiri. ${ }^{3}$ Denyut jantung memengaruhi waktu diastolik sehingga berpengaruh juga terhadap perbedaan tekanan tersebut. ${ }^{9}$ Semakin lambat denyut jantung seseorang, maka semakin lama periode diastolik dan semakin kecil perbedaan tekanan antara atrium kiri dan ventrikel kiri. Keadaan sebaliknya terjadi pada pasien dengan denyut jantung yang cepat (takikardia). Pengisian diastolik yang singkat akan memperbesar perbedaan tekanan antara ruang-ruang jantung kiri.

Pada pasien dengan fibrilasi atrial, periode diastolik akan berbeda-beda pada setiap denyutnya. Hal ini akan menimbulkan variabilitas perbedaan tekanan di ruang-ruang jantung kiri. Saat ini belum dapat dilakukan pemeriksaan yang bersamaan antara ekokardiografi dengan CSP sehingga sangat sulit untuk menganalisis data tersebut

\section{SIMPULAN}

Interval S2-OS memiliki korelasi yang snagat kuat dengan MVA. Klinisi dapat menentukan estimasi MVA dari interval S2-OS dengan menggunakan suatu persamaan. Interval S2-OS dapat diperoleh dengan alat sederhana melalui metode CSP.

\section{LIMITASI}

Penelitian ini menggunakan sampel yang relatif kecil dan belum ada validasi terhadap persamaan estimasi MVA tersebut. Penelitian lebih lanjut diperlukan untuk melakukan validasi tersebut sehingga hasilnya dapat dipertanggungjawabkan. Selain itu, penelitian ini mengekslusi pasien-pasien dengan fibrilasi atrial se- hingga persamaan tersebut tidak dapat diaplikasikan pada pasien-pasien fibrilasi atrial.

Telah dibawakan dalam Indonesian Cardiovascular Research Forum pada the 22nd Annual Scientific Meeting of Indonesian Heart Association (Asmiha), Jakarta, Indonesia, 5-7 April, 2013.

\section{DAFTAR PUSTAKA}

1. Edwards MM, O'Gara PT, Lily LS. Valvular heart disease. In: Lily LS, editor. Pathophysiology of Heart Disease (Fifth Edition). New York: LWW, 2010; p.197-223.

2. Yadav P, Joshi P, Gupta J, Joseph D, Sakhi P. Prevalence of rheumatic fever and rheumatic heart disease in school children in Malwa Region of MP. NJCM. 2010;1(2):156-8.

3. Carabello BA. Modern management of mitral stenosis. Circulation. 2005;112(3):432-7.

4. Ostfeld RJ. Mitral stenosis. In: Solomon SD, editor. Essential Echocardiography. New Jersey: Humana Press, 2007; p.239-54

5. Wolferth CC, Margolies A. The opening snap in mitral stenosis, its characteristics, mechanism of production and diagnosis importance. American Heart Journal. 1932;7(4):443-70.

6. Sarbandi RR, Doyle JD, Navidbakhsh M, Hassani K, Torabiyan H. A color spectrographic phonocardiography applied to the detection and characterization of heart murmurs: Preliminary results. BioMedical Engineering Online [serial online]. 2011 [cited 2013 Aug 10]; 10:42. Available from: doi:10.1186/1475-925X-10-42.

7. Kalmanson D, Veyrat C, Bernier A, Witchitz S, Chiche P. Opening snap and isovolumic relaxation period in relation to mitral valve flow in patients with mitral stenosis. Significance of A2--OS interval. British Heart Journal. 1976;38(2):135-46.

8. Ebringer R, Pitt A, Anderson ST. Haemodynamic factors influencing opening snap interval in mitral stenosis. British Heart Journal. 1970;32(3): 
128 Jurnal Biomedik (JBM), Volume 5, Nomor 2, Juli 2013, hlm. 123-128

$350-4$.

9. Stein E, Lau SH, Cohen SI, Helfant RH,

Haft JI, Damato AN. Effects of heart rate on left atrial pressure in mitral stenosis. Ann Intern Med. 1968; 68(5):1163-4. 